\title{
Versatile Performance in Vuca World: A Case Study
}

\author{
Debarun Chakraborty*
}

\begin{abstract}
Versatile execution in the workplace refers to adapting to changes in the working environment. It can be understood as adjusting conduct to meet new concerns owing to changing and dubious work circumstances. In situations characterised by volatility, uncertainty, complexity and ambiguity (VUCA), versatile execution is significant. This paper investigates how and where versatile execution can be understood, examined and analysed under the imperatives and rules for VUCA conditions.
\end{abstract}

Keywords: VUCA, Versatile Performance, Training and Learning

\section{Introduction}

The qualities and characteristics of the 21st century symbolise volatility, uncertainty, complexity and ambiguity and therefore are close to the characteristics of VUCA. Kinsinger and Walch (2012) expressed that the idea of VUCA was presented by the U.S. Armed Force War College to depict the unstable, dubious, mind-boggling and equivocal, multilateral world which came about after the end of the Cold War. This is how it was embraced by the vital business pioneers, to depict the disordered, fierce, and quickly changing business condition that has turned into the 'new normal' (Kishinger \& Walch, 2012). The four VUCA measurements can be clarified as here under: Volatility: Dynamic, snappy and serious changes in the

* Department of Management Social Science, Haldia Institute of Technology, Haldia, West Bengal, India; debarun84@gmail.com 
world; Uncertainty: An absence of consistency around issues and occasions where the idea of the occasion might be known, yet it is difficult to foresee its quality or results ahead of time; Complexity: The mix of issues and the disorder that encompasses any association, in which the circumstance has many interconnected parts and factors where a portion of the data might be accessible or could be anticipated, yet the volume or nature of it could be too overpowering to even think about processing; Ambiguity: The diffuseness of the real world and the blended implications of conditions in which connections are blurry, where no point of reference exists and where there is a need to confront the unknown.

Owing to the unpredictability, vulnerability, and intricacy, because of the changes happening in the present associations, versatile execution has turned out to be progressively vital in workplaces. As indicated by Hoover and Feldhusen (1990), versatile execution is considered a general insight that builds comprehension and critical thinking which makes imaginative critical thinking possible and easier to execute.

\section{Literature Review}

Anita Sarkar (2015) studies the protocols by which understand how our organisations have considerably changed within 10 years. The term VUCA that represents unpredictability, vulnerability, multifaceted nature and vagueness has turned out to be a normal expression today. Quick changes occurring in political, financial, social and mechanical fronts are expanding VUCA in the hierarchical world. Manwani (2013) emphasises that unpredictability and vulnerability have become normalised. Das and Ara (2014) found that we are moving from a universe of issues, which requests speed, examination, and vulnerability to explain, to a universe of quandaries, which requests tolerance, sense making and a commitment with vulnerability. VUCA (Volatile, Uncertain, Complex and Ambiguous) has the qualities of current key quandaries that require an alternate introduction and a lot of aptitudes.

Betof, Owens and Todd (2014) observe that the once recognisable limits of our commercial centers and businesses have now turned 
out to be penetrable. In this condition, one must understand that a reasonable future is just conceivable if associations can detect, adjust, and react to change; in the event that they can help their associations advance in and with a developing world. The latest worldwide depression of 2007 has added to the concerns that the recent decade has seen numerous enterprises undergo progressively quick changes that would have been unique 10 years ago.

\subsection{Versatile Performance in Training and Learning}

Execution situated learning is used for building abilities enabling versatile conduct to bargain effectively with either space explicit issues or issues emerging on the cross segments of various expert fields (Kommers et al., 2008). The improvement of versatile programming applications for instructive and preparing purposes has been important as well (Corbalán-Pérez, Kester \& van Merriënboer, 2006; Merrill, 2002; Oughton \& Reed, 2000; Wisberg, 2003).

Examination on versatile execution inside explicit settings, especially preparing and learning situations are being conducted now (Lang \& Bliese, 2009; LePine et al., 2000). The creators (Han \& Williams, 2008) also examined versatile execution for investigating the association of individual and group level connections. In a regularly evolving (VUCA) condition, associations should grow progressive, versatile and responsive authority abilities. The administration is no longer essentially the core and exclusive area of our senior supervisory groups, in VUCA, workers need to be prepared to relate, interface and react to difficulties and openings. The requirement for new initiative methodologies for driving an association in unpredictable and unverifiable occasions suggests a capacity to comprehend the circumstances and logical results and arrive at a conclusion to reveal openings that are not yet clear. Be that as it may, it includes the capacity to see what is beyond the horizon of our present field of view, getting profound instinct and utilizing the creative ability to imagine the future point.

An examination directed by Griffin et al. (2010) conveyed that the improvement of versatile and proactive execution will clarify the longitudinal point of view. Harvard Business Review have 
demonstrated a strong connection between abilities of authority and the real situations wherein organisations who can pull in the best individuals and who can lead were identified. However, numerous associations neglect to perceive the ability required in the association, the battle to distinguish potential or mismanage the advancement needs of high-potential individuals.

Bassie and McMurrer (2007) likewise argued that the setting with versatile execution should have the capacity to learn quickly, constantly convey and include, and be adaptable in their reactions and create just-in-time arrangements instead of sitting tight for impeccable arrangements. Singular work execution is an important issue which assumes a critical job in everyday working environment that has been studied in connection to wellbeing, specifically, work and authoritative wellbeing (Waldman, 1994; Evans, 2004; Campbell, 1990, Koopman et al., 2011).

In all the exploration fields referenced before, singular work execution is a dynamic, inactive build that can't be indicated or estimated specifically. While setting with versatile execution, Evans (2004) characterized work execution as an entirely scalable activity.

Han and William (2015) inspected the relationship of versatile execution at individual and group levels. Furthermore, they recommended the strategies for evaluation at various levels. Burke etal. (2006) studied group adjustment in relatuion to understanding its theoretical prospects. Execution of emotionally supportive networks in business and industry can targetincrement in individual and authoritative execution. VUCA is a 'situational indicative'. It focuses on the present setting confronting associations and pioneers and gives the indispensable points of view that are then changed over into an activity plan. It is an activity situated apparatus, intended to illuminate, prepare and manage initiative activity. The VUCA demonstrates and recognizes the inner and outside conditions influencing associations today. The VUCA Prime was produced by Bob Johansen, a distinguished fellow at the Institute for the Future and the creator of Leaders Make the Future: Ten New Leadership Skills for an Uncertain World. He suggests that the best VUCA pioneers are described by vision, comprehension, clearness, and readiness the 'flips' to the VUCA model. It very well may be viewed as the continuum of 
skills thatpioneers can develop to help make sense of leading in a VUCA world. HR and talent management professionals can use VUCA Prime as a 'skills and abilities' blueprint while making leadership development plans (Lawrence, 2013). Koopmans et al. (2011) endeavored to portray reasonable structures of individual work performance through a survey. Kenney (2009) expressed the key issues related to the difficulties that needs to be analysed as a versatile association in VUCA condition. Kenney expressed that to line up with changes, an association needs to concentrate on the five territories to stay significant and powerful in the face of progress and dynamism. Versatile conduct appraisal or evaluation of the day by day execution of exercises is essential for individual and social adequacy.

Campbell, Smith and Wool (1981) likewise built versatile conduct scale for surveying the difference in scores of rationality in individualswho were referred for the organization. Heath (1986, April) inclined towards versatile conduct, studying the previous decades and expressed where and how the exploration inclined towards versatile conduct advances. The investigations on evaluation and on the endeavor to survey versatile conduct with regards to rationally hindered individuals in the USA and other western nations have already begun in 1967. After observing that from 1981 to 2014 the pattern of developing such scale was more, huge numbers of a similar investigation was focused for the most part on the adaptiveness of rationally hindered or challenged subjects on enthusiasm under the order of restorative brain research. These scales did not focus on versatile execution in the work put. In the evolving condition, staff jobs, obligations and working connections have seen changes; the meaning of occupation execution has additionally turned out to be increasingly intricate, equivocal and dynamic, and changes in working life has also become difficult (Chan, 2001). In all representative execution, versatile execution in the workplace refers to adaptingto and understanding change in the work environment. Heath and Obrzut (1984) illustrated the versatile behavior of the 'rational' people in the field of VUCA. Campbel (1990) in his work demonstrated the execution forecast issues in mechanical and authoritative brain research where he/she consolidated versatile execution issues. 


\section{Conclusion}

The VUCA world will remain. As innovation grows quicker and the world moves toward becoming increasingly more towards a worldwide commercial center, there is no place to stow away. Change is determined and the scene in which we work is always moving. Responding without having vision leave individuals feeling befuddled and demotivated. Inflexibility could be a bane in this context. VUCA is unpredictable and testing, yet it is additionally a domain that can permit genuine administration aid to develop all dimensions of the association. In fact, one of the significant exercises of the VUCA world is that the pioneers need to connect all representatives in all dimensions to employ trust and commitment in managing the incredible scope of difficulties that VUCA presents.

\section{References}

Bassie, L. \& McMurrer, D. (2007). Maximizing your return on people. Harvard Business Review, 115-124.

Betof, E., Owens, L. M., \& Todd, S. (2014). Leaders as teachers action guide: proven approaches for unlocking success in your organization. American Society for Training and Development.

Burke, B. (2016). Gamify: How gamification motivates people to do extraordinary things. Routledge.

Campbell, V., Smith, R. \& Wool, R. (1981). Also constructed adaptive behavior scale for assessing the difference in scores of mentally retarded individual referred for institutionalization, those never referred. American Journal of Mental Deficiency, 86, 425-428.

Chan, D. (2001). Conceptual and empirical gaps in research on individual adaptation at work. In C. Cooper \& I. Robertson (Eds.), Organizational Psychology and Development, 1-22.

Corbalan, G., Kester, L. \& Van Merriënboer, J. J. G. (2006). Towards a personalized task selection model with shared instructional control.Instructional Science, 34(5), 399-422.

Das, K. K. \& Ara, A. (2014). Leadership in VUCA World: A case of Lenovo. International Journal of Current Research, 6(4), 6410-6419.

Ewans, M. (2004). Conflict in Afghanistan: Studies in Asymetric Warfare. Routledge. 
Griffin, M., Parker, S. \& Mason, C. (2010). Leader vision and the development of adaptive and proactive performance: A longitudinal study.Journal of Applied Psychology ,95, 174-182.

Han, T. Y., \& Williams, K. J. (2008). Multilevel investigation of adaptive performance: Individual-and team-level relationships. Group $\mathcal{E}$ Organization Management, 33(6), 657-684.

Han, T. Y. \& Williams, K. J. (2008). Multilevel investigation of adaptive performance: Individualand team-level relationships. Group $\mathcal{E}$ Organization Management, 33, 657-684.

Heath, C. P. \& Obrzut, J. E. (1984). Comparison of three measures of adaptive behavior. American Journal of Mental Deffiency, 89, 205-208

Heath, C. P. (1986). Trends in adaptive behavior research over the past decade. Paper presented at the meeting of the National Association of School Psychologist, Hollywood, FL.

Hoover, S. M. \& Feldhusen, J. F. (1990). The scientific hypothesis formulation of ability of gifted ninth grade students. Journal of Educational Psychology, 82, 838-848.

Hough G.H. (Eds.). Handbook of Industrial and Organisational Psychology (vol 1, pp 687-732). Palo Alto: Consulting Psychologist Press.

Kenney, S. (2009). The adaptive organization: Fostering change in five areas. Retrieved from http:// www.amanet.org/ training/ articles/ The-Adaptive-Organization-Fostering-Change-in-Five- Areas.aspx

Kingsinger, P. \& Walch, K. (2012). Living and leading in a VUCA world. Thunderbird University. http:// knowledgenetwork. thunderbird. edu/ research/2012/07/09/ kinsinger-walch0vuca/.

Kommers, P., Stoyanov, S., Mileva, N. \& Mediano, K. M. (2008). The effect of adaptive performance support system on learning achievements of students. International Journal of Continuing Engineering Education and Lifelong Learning, 18(3), 351-365.

Koopmans, L., Bernaards, C. M., Hildebrandt, V. H., Schaufeli, W. B., de Vet Henrica, C. W. \& van der Beek, A. J. (2011). Conceptual frameworks of individual work performance: A systematic review. Journal of occupational and environmental medicine, 53(8), 856-866.

Lang, J. W. B. \& Bliese, P. D. (2009). General mental ability and two types of adaptation to unforeseen change: Applying dis-continuous growth models to the task-change paradigm. Journal of Applied Psychology, 94, 411- 428.

Lawrence, K. (2013). Developing leaders in a VUCA environment, UNC Kenan - Flagler Business School, UNC Executive Development.

LePine, J., Colquitt, J., \& Erez, A. (2000). Adaptability to changing task contexts: Effects of general cognitive ability, conscientiousness, and openness to experience. Personnel Psychology, 53, 563-593. 
Manwani, H. (2013). Speech delivered at the Annual General Meeting. Hindustan Unilevel Limited.

Merrill, M. D. (2002). Instructional strategies and learning styles: Which takes precedence? In R.A. Reiser \& J.V. Dempsey (Eds.), Trends and Issues in Instructional Technology (pp. 99-106)Columbus, OH: Prentice Hall.

Sarkar, A. (2015). We live in a VUCA World: The importance of responsible leadership. Emerald Group Publishing, Development and Learning in Organizations, 30(3), 1-9.

Waldman, D. A. (1994). The contributions of total quality management to a theory of work performance. Academy of Management Review, 19(5), 10-536. 